\title{
ASPECTOS DA PRESENÇA RELIGIOSA EM LONDRINA: SITUANDO UMA PESQUISA
}

\author{
Alexandre Brasil Fonseca \\ Professor do Departamento de Ciências Sociais \\ da Universidade Estadual de Londrina
}

E-mail: brasil@uel.br

\section{Resumo}

Com base em levantamento realizado durante o ano de 2000 sobre as religiões em Londrina discutiremos a presença religiosa na cidade, visando oferecer elementos que auxiliem na percepção da extensão e das características gerais das crenças praticadas. Voltaremos nossa atenção especialmente para quatro grupos: católicos, evangélicos, espíritas e os "sem religião", salientando sua conformação mais geral no Brasil e a distribuição geográfica dos locais de culto/ missa na cidade. Por fim, apresentaremos alguns dados preliminares da pesquisa "Internacional Study of Esoterism and Religion", o qual tem sido desenvolvido em quinze países de três continentes entre 1999 e 2000, fazendo parte da segunda rodada sobre Religião do "International Social Survey Programme". No início de 2000 foi concluído o trabalho de campo, resultando em banco de dados com 3650 entrevistados e foi iniciada a etapa de tabulação e análise das informações. No Brasil a pesquisa foi desenvolvida na Universidade Estadual de Londrina e em outras quatro universidades. Em nossa conclusão indicaremos peculiaridades locais das religiões em comparação com o quadro nacional e apontaremos possíveis caminhos que serão desenvolvidos em nossa pesquisa sobre a religiosidade entre universitários em Londrina.

Palavras-chave: religiosidade em Londrina, religiões, universitários.

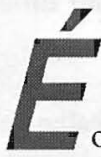

marcante a presença das religiões na cidade de Londrina, onde podemos observar ativa atuação de católicos e evangélicos, como também a prática, às vezes marginal, de grupos espíritas e a tradição preservada entre as famílias orientais de seus rituais e cultos. Também encontramos na cidade uma mesquita mulçumana, além de uma série de outros grupos alternativos que oferecem variadas opções místicas. 
Neste texto discutiremos a presença religiosa em Londrina de forma introdutória com o objetivo de situar o leitor em nossa pesquisa acerca da religiosidade entre os estudantes da Universidade Estadual de Londrina. Inicialmente trataremos dos quatro principais grupos religiosos existentes no Brasil, para então apresentarmos algumas questões relacionadas aos locais de culto/missa e sua distribuição/perfil na cidade. Em seguida apresentaremos de forma preliminar, características da religiosidade praticada pelos universitários da UEL, dados que fazem parte da pesquisa que estamos desenvolvendo em conjunto com alunos do curso de Ciências Sociais' dentro da segunda rodada sobre religião do ISSP (International Social Survey Programme) à qual foi denominada ISER (International Study of Esoterism and Religion, amog students), reunindo pesquisadores de 10 países $^{2}$. A coordenação internacional do projeto é do Dr. Franz Hollinger da Universidade de Graz/Áustria e no Brasil da Dra. Deis Siqueira da Universidade de Brasília.

\section{As religiões do Brasil}

Os dados oficiais disponíveis em relação à religião em Londrina são do censo de 1991, realizado pelo Instituto Brasileiro de Geografia e Estatística. Na Tabela 1 apresentamos esses resultados ao lado dos dados nacionais. Os números sobre opção religiosa coletados no censo 2000 somente estarão disponíveis no final de 2002.

Ao discutirmos o fenômeno religioso, interessa-nos especialmente as posições dos católicos, evangélicos, espíritas ${ }^{3}$ (afro-brasileiros e kardecistas) e os sem-religião. Dos levantamentos abrangentes realizados após o censo de 1991 no Brasil nos chama atenção uma

\footnotetext{
1 Agradeço aos alunos pela dedicação com que desenvolveram o trabalho de campo, especialmente a Adir Habonski, Alexander Kogurt, Anicéia Gomes, Daniele Monteiro, Jaqueline Ferreira, Walace Oliveira, Kizze dos Santos e Maria Luísa Marigo.

${ }^{2}$ Foram realizadas pesquisas em 16 universidades nos EUA, Itália, Áustria, Uruguai, Argentina, Alemanha, Inglaterra, Colômbia, Portugal e Brasil. Ao todo foram entrevistados 3659 universitários. Desses 1310 são brasileiros, das seguintes universidades: UnB, UFRGS, UFPb, UFG e UEL.
} 
pesquisa de 2000 promovida pela Brasmarket (Garçoni \& Vilas, 2000), em que foram entrevistadas 200 mil eleitores de 449 municípios. Nessa pesquisa os resultados foram bem próximos aos encontrados em levantamentos anteriores - um do IBOPE de 1998 e outro do Datafolha de 1994. Por esses dados podemos apontar algumas importantes alterações do campo religioso brasileiro, principalmente a significativa diminuição do número de católicos ao lado do incremento dos evangélicos e dos sem-religião.

\begin{tabular}{|c|c|c|c|}
\hline RELIGIÃO & $\begin{array}{c}\text { BRASIL } \\
\text { Fiéis }\end{array}$ & & $\begin{array}{c}\text { LONDRINA } \\
\text { Fiéis }\end{array}$ \\
\hline Católica Romana & 121.812 .771 & 82,97 & $307.489: 78,82$ \\
\hline Outra Cristã Tradicional & 553.949 & 0,38 & $618,0,16$ \\
\hline Evangélica Tradicional & 4.388 .284 & 1 2,99 & $17.693,4,54$ \\
\hline Evangélica Pentecostal & 8.179 .708 & I 5,57 & $34.308+8,79$ \\
\hline Cristã Reformada não determinada & 621.298 & 1. 0,42 & $1.320,0,34$ \\
\hline Neocristã & 875.219 & 0,60 & $3.682,0,94$ \\
\hline Espírita & 1.644 .355 & 1,12 & $3.485,0,89$ \\
\hline Candomblé e Umbanda & 648.489 & 0,44 & $\begin{array}{ll}725 & 0,19\end{array}$ \\
\hline Judaica ou Israelita & 86.416 & 0,06 & $38: 0,01$ \\
\hline Oriental & 368.578 & 0,25 & $4.516, \quad 1,16$ \\
\hline Outra & 94.556 & 0,06 & 93 । 0,02 \\
\hline Sem-religião & 6.946 .221 & 1. 4,73 & $15.707,4,03$ \\
\hline Sem declaração & 595.979 & 0,41 & $418,0,11$ \\
\hline Total & 146.815 .818 & 100 & $390.092 \quad 100$ \\
\hline
\end{tabular}

Fonte: Censo Demográfico 1991 - IBGE

Os dados da Brasmarket apontam uma diminuição de $16 \%$ dos católicos, aparecendo estes com $67 \%$ da amostra, enquanto no censo de 1991 o percentual era de $83 \%$ da população. Desde 1950 , quando abrangia $93 \%$ da população, a presença de católicos encontra-se em

\footnotetext{
'Optamos por chamar de Espíritas os adeptos tanto do kardecismo, como aqueles seguidores do Candomblé e da Umbanda. Outra opção para juntar os dois grupos seria de apontá-los como "religiões mediúnicas", optamos por utilizar o termo espírita pelo fato de seu uso ser naturalizado por participantes das religiões afrobrasileiras (Fonseca, 1995).
} 
constante declínio em nossa sociedade, fato que se deve grandemente à presença de um elevado número de "não-praticantes". O segundo grupo religioso em termos quantitativos são os evangélicos que em 1991 contavam com $9 \%$ da população e que na pesquisa da Brasmarket aparecem com $13 \%$. Em seguida temos os que se definem como semreligião, os quais nestes nove anos podem ter dobrado seu número. No Censo de 1991 estes aparecem com $4,7 \%$ enquanto na pesquisa de 2000 alcançam 9,5\%. Essa realidade dá aos sem-religião o status de "grupo religioso" que relativamente mais cresceu em nosso país na última década (Fonseca, 2001). Por fim temos o kardecismo e às religiões afro-brasileiras com o mesmo patamar tanto em 1991 como nas pesquisas mais recentes, indicando que seus fiéis assumidos têm acompanhado o crescimento vegetativo da população mantendo cerca de $1 \%$ de presença.

Em relação a Londrina não existem dados recentes, mas de um modo geral os números da cidade acompanham a realidade nacional. A exceção se deve à composição étnica diferenciada com alto número de orientais e com isso um maior número de adeptos dessas religiões e a uma maior presença dos evangélicos como apontam os dados do IBGE.

\section{Católicos, evangélicos, espíritas e os sem-religião}

Em primeiro lugar consideraremos os que se definem católicos. O que representa ser católico nos dias atuais? Certamente uma grande parte dos 79\% que se declararam católicos em Londrina no censo de 1991 podem ser incluídos no grupo dos chamados "católicos nominais", o que nos remete à discussão acerca da presença de "católicos praticantes" e de "não-praticantes", ou da tensão "Catolicismo em contraposição a Igreja Católica" (Mariz, 1989) ou da abordagem "Catolicismo Tradicional em contraposição a Catolicismo Internalizado" (Camargo, 1973) Como apontam Pierucci e Prandi:

"Dentre os católicos, a maioria ainda é constituída daqueles que aqui vamos chamar de católicos tradicionais, reunindo tanto os que frequientam a igreja esporadicamente como os que têm frequiência regular mas não se envolvem em movimento de renovação ou agremiações (...) de reavivamento da vida católica (...). Se a maioria católica é formada de católicos tradicionais, há por outro lado uma grande fatia de $13,5 \%$ de 
cidadãos brasileiros que vivem o catolicismo a partir de reorientação pessoal por uma das diferentes modalidades de internalização ou engajamento religioso." (Pierucci \& Prandi, 1996, p.215).

Além da baixa frequiência, também temos as discordâncias no que se refere às principais doutrinas católicas. Muitos fiéis desconhecem ou ignoram determinadas confissões da sua fé, o que faz com que, como demonstra levantamento feito por Piquet Carneiro \& Soares (1992, p. 40$)$, que quase metade $(45,9 \%)$ dos que freqüentam regularmente a Igreja Católica acreditem na doutrina espírita - negada pelo catolicismo - da reencarnação. Dentro do catolicismo devemos considerar a presença de, pelo menos, três grandes grupos. Primeiramente temos o catolicismo tradicional, onde está a grande massa dos adeptos, sendo que - segundo Pierucci e Prandi (1996) - somente um terço destes estaria desenvolvendo algum tipo de engajamento religioso, seja pela participação em alguma pastoral específica seja por práticas religiosas regulares como a eucaristia, participação em romarias ou mesmo a presença na missa.

Além destes teríamos outros envolvidos diretamente em dois grupos que se destacam. Temos a presença nas Comunidades Eclesiais de Base (CEBs) e seu envolvimento com a Teologia da Libertação que no passado mereceu grande atenção da Sociologia da Religião. Com uma forte proposta de engajamento social as CEBs tiveram seu ápice na década de 1980, entrando em declínio a partir dos anos de 1990.

Vários são os motivos e as discussões em torno da história do enfraquecimento das CEBs. Hoje ainda existem vários focos organizados e atuantes, os quais adotam práticas desse movimento religioso que tem como referência a vivência comunitária e a presença entre as camadas populares, `a base. Com sua estrutura participativa e reivindicatória as CEBs contribuíram para a organização de muitos dos movimentos sociais estabelecidos nos últimos anos, sendo que dentro da universidade é a Pastoral Universitária (PU) o grupo que adota o maior número de valores e conceitos difundidos pelas CEBs de envolvimento com o câmpus e com a realidade universitária.

Recente artigo defende que as CEBs devem dar mais atenção aos aspectos místicos da vida para continuarem sua presença na sociedade (Steil, 1998). É exatamente nesses aspectos que a Renovação 
Carismática Católica (RCC), ramo pentecostal atuante no seio da Igreja Católica há 30 anos, destaca-se ao lado de sua ênfase no indivíduo e das constantes "aeróbicas do Senhor" que são transmitidas regularmente pelos dois canais de televisão controlados por grupos pertencentes a RCC (Canção Nova e Rede Vida).

Dentro das universidades a RCC se faz presente graças à ação dos Grupos de Oração Universitários (GOU). Com proposta bastante distinta da adotada pelas PUs, os GOUs têm como objetivo promover espaços de encontro e de práticas religiosas dentro das instituições de ensino, sem o objetivo de interferir em seu cotidiano. O que importa são as pessoas que ali se reúnem em busca de enlevo espiritual ou de orações para enfrentarem seus problemas.

Quando falamos em católicos devemos ter em mente a massiva existência dos chamados "nominais", ao lado dos que vivem uma religião internalizada, tanto em grupos específicos como a RCC e as CEBs ou mesmo em práticas tradicionais regulares. No primeiro grupo estão quase $60 \%$ dos brasileiros. Pessoas que se definem como católicas, mas que efetivamente não participam minimamente dessa religião. Fernandes (1994) aponta que 60\% dos católicos não freqüentam missas ou outras reuniões, enquanto somente $20 \%$ participa semanalmente e outros $20 \%$, mensalmente. Entre os evangélicos o percentual de participação semanal é de $80 \%$ e tanto no kardecismo como no candomblé a participação mensal e semanal é uma realidade para $80 \%$ dos fiéis (entre os evangélicos chega aos $90 \%$ ).

O segundo grupo que nos interessa definir mais detidamente é o dos evangélicos. Neles estão incluídos uma significativa variedade de segmentos e realidades. Tanto os chamados "crentes" como os tradicionais "protestantes" podem ser considerados evangélicos. Em Londrina a presença evangélica é mais significativa do que a existente no conjunto da população brasileira (Tabela 1). A presença dos evangélicos no Brasil se dá no início do século passado com a chegada de imigrantes alemães que fundam, no sul do País, a Igreja Evangélica de Confissão Luterana no Brasil (1824). Até os dias atuais a igreja distingue-se por esse componente étnico, 95\% de seus membros são brancos (a porcentagem de brancos na população brasileira é de $52 \%$ ). 
Em meados do século XIX começam a chegar missionários provenientes dos Estados Unidos com o objetivo de fundar novas igrejas. Até o final daquele século são estabelecidas sete denominações: Congregacional (1855), Presbiteriana (1859), Metodista (1867), Adventista (1894), Cristã Evangélica (1879), Batista (1882) e Anglicana (1898). Essas igrejas, juntamente com os luteranos, caracterizam-se como provenientes da Reforma Protestante e representam o protestantismo histórico ou os evangélicos tradicionais.

É no século XX que têm início no Brasil as atividades das primeiras igrejas pentecostais, as quais se caracterizam pela glossolalia (falar em outras línguas) e pela crença na contemporaneidade dos dons do Espírito Santo. Em 1910 o italiano Luigi Francescon chega ao interior de São Paulo e funda a Igreja Congregação Cristã, e em 1911 os suecos Gunnar Vingren e Daniel Berg fundam em Belém do Pará, norte do País, a Assembléia de Deus, igreja com maior número de templos em Londrina e maior denominação evangélica, atingindo cerca de $3 \%$ da população (Garçoni \& Vilas, 2000). Tanto Francescon como Vingren e Berg tiveram sua experiência pentecostal nos Estados Unidos, em uma igreja que se reunia em Los Angeles, na Rua Azuza.

Dentro do pentecostalismo ainda temos outros dois grupos. Os deuteropentecostais (Mariano, 1999), o qual reúne igrejas de meados do século e que tem na Igreja do Evangelho Quadrangular (1951), na O Brasil Para Cristo (1955) e na Deus é Amor (1962) seus principais representantes e que colocam na "cura divina" a principal ênfase de sua pregação. Tanto a Assembléia como a Congregação Cristã focam sua mensagem na pregação da salvação, sendo conhecidas como representantes do pentecostalismo clássico.

A partir de meados da década de 1970 são fundadas as igrejas que ficaram conhecidas como neopentecostais e que se caracterizam pelo intenso uso dos meios de comunicação eletrônicos, pela utilização de sessões de cura e exorcismo, por um menor rigor e exigência em relação aos hábitos e ao vestuário e pela divulgação da Teologia da Prosperidade. A principal e mais famosa representante desse grupo é a Igreja Universal do Reino de Deus, fundada em 1977 e que tem na figura do bispo Edir Macedo seu líder mundial. A Igreja Universal encontrase em todos os continentes, com presença em mais de 50 países, mas é 
na África, Portugal e Argentina (além do Brasil) onde tem experimentado maior sucesso. Outra igreja desse grupo é a Igreja Internacional da Graça de Deus (1980), fruto de uma primeira divisão da Igreja Universal, cujo líder é o missionário R. R. Soares. Na UEL é por intermédio da Aliança Bíblica Universitária (ABU) que os evangélicos - pentecostais e tradicionais - se reúnem.

A terceira opção religiosa sobre a qual gostaríamos de nos deter é a opção de não ter religião. Entre 1980 e 1991 o percentual dos que se declararam como sem-religião cresceu $250 \%$ e a pesquisa da Brasmarket encontrou 9,5\% de entrevistados que afirmaram não seguir nenhuma religião. Com maior crescimento relativo, os "sem-religião" vão-se tornando cada vez mais numerosos e passam a representar significativo grupo na composição do campo religioso brasileiro. As explicações que consideram a pluralização do campo religioso com base na teoria da secularização (Pierucci, 1997) parecem-nos mais adequadas para entendermos essa realidade que se torna cada vez mais significativa e presente em nossa sociedade.

Qual é a origem dos "sem-religião"? Que confissão religiosa possuíam antes de decidirem não mais seguir uma religião? ${ }^{\dagger}$. Não devemos confundir esse grupo com agnósticos, ateus ou céticos, mas sim com pessoas que constroem sua própria religiosidade a partir das diferentes opções oferecidas em nossa sociedade. Pesquisa realizada por Gómez (1996) trabalhou com o crescimento e a deserção na Igreja Evangélica da Costa Rica. Por meio de amplos levantamentos nacionais o autor encontrou uma relação entre crescimento e deserção nas igrejas evangélicas. Pesquisa realizada pelo Instituto Gallup em 1989 indicou que, enquanto $8,9 \%$ da população era evangélica, outros $8,1 \%$ já tinham sido evangélicos em algum momento de suas vidas, e em 1991 os evangélicos chegaram a $10,6 \%$ da população enquanto os "ex-evangélicos", a 12,1\%. Em seu livro Gómez demonstra que cerca da metade dos egressos de igrejas evangélicas decidiu-se por não pertencer a nenhuma religião, sendo que em algumas cidades esse percentual chegou a $86 \%$.

A explicação que nos parece mais interessante - não por uma possível capacidade racionalizante, mas pelo desraizamento que pro-

\footnotetext{
${ }^{4}$ Para maiores detalhes em relação aos sem-religião ver Fonseca, 2001.
} 
duz - é a que relaciona o crescimento evangélico e a conseqüente pluralização do campo religioso com a intensificação do processo de secularização em nosso país. Como salientou Pierucci (1997, p.115) "pluralismo religioso não é apenas resultado, mas "fator" de secularização crescente", a atual efervescência religiosa experimentada no Brasil favorece o desenraizamento dos indivíduos da cultura tradicional (no caso, católica) o que acaba por fortalecer o aumento dos que se definem como sem-religião e o processo de secularização. As pessoas percebem que é possível a mudança e se abrem à possibilidade de se quebrar vários códigos sociais, de romper com a tradição. Dado o primeiro passo, as conseqüências se apresentam de forma variada, viabilizando potencialmente a negação de pertença religiosa, pois a mudança religiosa significa "romper com a própria biografia" (Pierucci \& Prandi, 1996, p.18).

É difícil pensarmos em organizações que reúnam pessoas semreligião, apesar que na universidade há grande presença de pessoas que assim se classificam. A média geral dos que declararam não possuir religião chegou a $16 \%$ no ISER, atingindo $43 \%$ dos universitários entrevistados na Inglaterra, $32 \%$ na Alemanha e $28 \%$ em Portugal. Curiosamente temos recentemente (1999) em nosso país a formação de dois grupos organizados de pessoas sem-religião: a Sociedade da Terra Redonda, uma organização não-governamental que tem como objetivo "defender os direitos dos ateus e das atéias na sociedade, advogar pela total e completa separação entre religião e governo, e divulgar o método científico, as realizações e os avanços da ciência", e o Fórum Cético Brasileiro que reúne 325 pessoas em uma lista na Internet e que busca organizar um movimento cético estruturado no Brasil.

O quarto e último grupo que nos interessa reúne os espíritas kardecistas e os afro-brasileiros. Iniciado no final do século XIX o espiritismo kardecista representa uma interessante religiosidade. Com as idéias de Allan Kaderc sendo difundidas no Brasil ao mesmo tempo em que as mesmás eram produzidas na França, aqui o espiritismo se caracterizou menos como a "ciência de observação" imaginada por seu fundador para se tornar mais uma "religião" a partir da prática da Federação Espírita Brasileira, Casa-Máter do Espiritismo Brasileiro. Porém essa tensão entre "religião e ciência" continua permanente no grupo, expressando-se ora como "religião científica" ora como "ciência religiosa" (Giumbeli, 1997). 
Essa dupla pertença certamente contribui para sua maior presença nos ambientes universitários brasileiros, o que não ocorre nos outros países em que foi realizada a pesquisa. No Brasil faz parte do senso comum considerar o espiritismo mais uma religião entre as muitas existentes, levando a um percentual de 11 os universitários que professam essa crença entre os 1310 entrevistados por nossa pesquisa no Brasil. Apesar da proximidade geográfica e cultural, e mesmo assim com percentuais bem baixos, somente no Uruguai $(1,12 \%)$, na Argentina $(0,7 \%)$ e em Portugal $(0,6 \%)$ encontramos referências ao espiritismo como religião entre os respondentes. Nas universidades os espíritas se organizam a partir do Núcleo Espírita Universitário (NEU), o qual oferece ligações com grupos de diferentes localidades, promovendo o intercâmbio de pessoas, além de eventos. Também são comuns os livros e vídeos doados pelo NEU às universidades.

O candomblé e a umbanda representam uma espécie de religiosidade mágica (Prandi, 1996a) que se destaca pelos rituais repletos de dança e de músicas, sempre marcados pela celebração e pelo exagero nas vestimentas e na estética. Como religião mágica o candomblé não impõe uma ética/moral aos seus fiéis, representando mais uma série de práticas que buscam manipular o mundo real por intermédio de ações que movimentam o mundo dos espíritos (Prandi, 1996a).

As divindades do candomblé se caracterizam por possuírem tanto aspectos positivos como negativos e daí, a partir da definição do "orixá de cabeça", os fiéis encontram várias explicações para o seu comportamento e conduta. Temos nessa religiosidade a ausência da concepção de certo ou errado, o que leva à definição emitida por Prandi (1996), de que o candomblé é como uma religião pós-ética e pré-ética simultaneamente. É pré-ética ao abrigar amplos setores excluídos e marginalizados de nossa sociedade que não encontram acesso às mínimas realizações de nossa época na ciência e na tecnologia, e é ao mesmo tempo pós-ética ao se configurar como uma opção religiosa concreta para aqueles que já usufruíram grande parte desses avanços e vivem intensamente o individualismo de nossa época. De um lado o candomblé inclui uma grande massa de negros e pobres, de outro causa fascínio entre intelectuais, políticos, artistas, e professores universitários (Leite, 1996; Paiva, 1999). 
Sobre a umbanda cabe apontar sua origem em 1930 no Rio de Janeiro e sua configuração como uma religião urbana e branca, à qual representa a união de crenças oriundas do catolicismo, do espiritismo e do candomblé. Essa união realizada em nosso país confere à umbanda a marca de "religião brasileira" (Concone, 1987), a qual apresenta-se como uma religião aberta a todos, tendo seu ritual de iniciação muito mais simplificado do que o do candomblé e com a ausência dos sacrifícios com sangue. Em Londrina encontramos uma espécie de "candomblé umbandizado" , onde as posturas "ortodoxas" do candomblé são atenuadas pela adoção de práticas da umbanda que por ser uma religião universal acaba sendo mais facilmente praticada e difundida. $\mathrm{Na}$ existem grupos nacionalmente organizados que representem essas religiões nas instituições de ensino superior.

\section{Distribuição geográfica das religiões em Londrina}

O Departamento de Pesquisa do Serviço para Evangelização da América Latina ( SEPAL) em cooperação com dois seminários evangélicos da cidade promoveu o Projeto Londrina 2000 onde foram mapeados todos os locais de culto das diferentes religiões que se reúnem na cidade. Esse levantamento encontrou 513 locais, entre templos, paróquias, igrejas, terreiros, centros e outros espaços onde práticas e rituais religiosos são executados. Uma observação mais detida desses dados fornece interessante material de investigação para se compreender a religiosidade na cidade.

Dos 513 locais de culto, 353 são evangélicos, sendo que cerca de $70 \%$ desse total são espaços pertencentes a igrejas pentecostais. Os católicos possuem 76 estabelecimentos e os espíritas 54 ( 35 afro-brasileiros e 19 kardecistas). Apesar da significativa presença de pessoas vinculadas às religiões orientais (Tabela 1), na cidade existem poucos locais onde os pertencentes a essas religiões podem-se reunir. Sobre a concentração desses locais na cidade de Londrina o Quadro 1 é ilustrativo.

5 Conforme comunicação oral do prof. Sérgio Paulo Adolfo sobre o tema, ver Adolfo, 1997. 


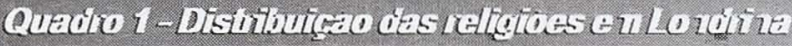

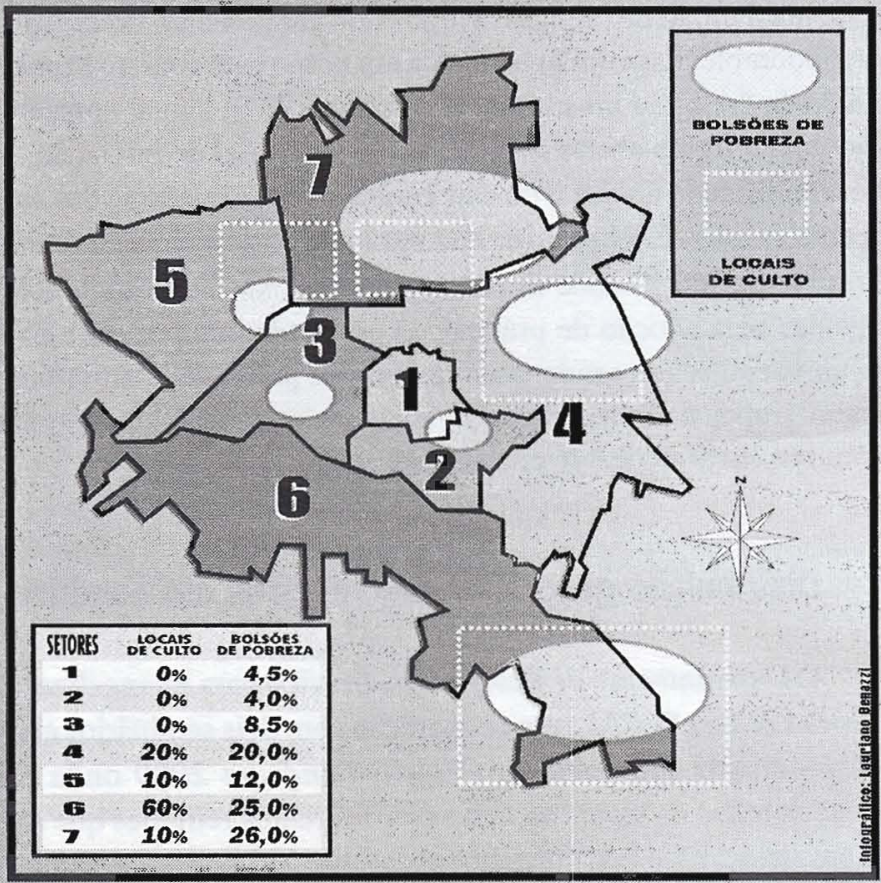

Fontes: Projeto Londrina 2000 (SEPAL) e Plano Diretor (IPPUL), 1995

Em relação a esses dados é importante salientar a pulverização característica das iniciativas evangélices. Dos 353 locais pertencentes ao grupo, 148 são de denominações com menos de três templos na cidade e somente 27 denominações evangélicas possuem uma presença mais consolidada e em mais de duas localidades. Destacam-se a Assembléia de Deus (51), os presbiterianos (31), a Congregação Cristã (23), os batistas $(21)^{6}$, os da Deus é Amor (19) e os adventistas (18) ${ }^{7}$.

As maiores concentrações religiosas ocorrem nos extremos norte e sul da cidade, locais onde também se encontram os principais bolsões de pobreza, como aponta o Mapa da Fome desenvolvido em 1994 pelo Laboratório de Geografia Humana da UEL. Juntos os setores 7 e 6 da 
cidade (norte e sul na divisão adotada pela prefeitura) abrigam um pouco mais de $50 \%$ dos locais de culto da cidade. Essa maior presença é devida principalmente à ação dos evangélicos que concentram os seus templos nessa região, estabelecendo uma presença bem mais significativa do que as outras religiões.

É fato que em todas as religiões aqui discutidas há maior presença de locais de reunião no norte e no sul de Londrina. $\mathrm{O}$ diferencial é que a concentração evangélica (com 353 locais, em contraposição aos 75 dos católicos e aos 54 dos espíritas) tem maior peso relativo, como no caso da cidade do Rio de Janeiro (Fernandes, 1994). Para termos uma idéia mais precisa dessa presença podemos observar a Tabela 2 onde a relação entre número de habitantes e templo é apresentada.

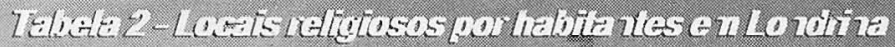

\begin{tabular}{c|c|c|c}
\multicolumn{2}{c|}{ Locais/10.000 habitantes } & Espíritas & Evangélicos \\
Setor & Católicos & 0,1 & 1,5 \\
$\mathbf{1}$ & 1,0 & 1,8 & 1,8 \\
$\mathbf{2}$ & 0,7 & 0,8 & 6,5 \\
$\mathbf{3}$ & 1,0 & 0,5 & 8,1 \\
$\mathbf{4}$ & 1,6 & 0,9 & 9,2 \\
$\mathbf{5}$ & 2,2 & 2,3 & 12,1 \\
$\mathbf{6}$ & 2,3 & 1,3 & 11,0 \\
$\mathbf{7}$ & 2,3 & &
\end{tabular}

Fontes: Projeto Londrina 2000 (SEPAL) e Plano Diretor (IPPULL), 1995

O Setor 1 (Centro) caracteriza-se por uma significativa presença católica e de evangélicos tradicionais, representando os dois grupos quase $80 \%$ dos locais de culto na região. No Centro só há um centro espírita e três igrejas pentecostais em todos os outros locais da região

${ }^{6}$ Entre os presbiterianos reunimos os templos da Igreja Presbiteriana do Brasil e da Igreja Presbiteriana Independente e entre os bastistas temos a reunião dos templos da Convenção Batista Brasileira e de várias outras pequenas denominações que possuem "batista" em seu nome.

7 Os adventistas representam um grupo "de fronteira" em relação a sua inclusão ou não como evangélicos. Sobre essa discussão ver Fonseca (1997) e D’Epinay (1975). 
estão católicos ou evangélicos tradicionais. Já o Setor 2 (final da Av. Duque de Caxias com Av. Paul Harris) possui interessante característica. Nele há predominância de locais de culto espíritas. De todos os centros e terreiros da cidade $15 \%$ se encontram na região, enquanto no mesmo setor existem apenas $3 \%$ dos templos evangélicos e $4 \%$ das igrejas católicas. Os Setores 6 e 7 concentram a maior presença de todas as religiões e o Setor 2 a menor, não fosse exceção os espíritas, cuja presença no Setor 2 ocupa a terceira colocação em número de locais de reunião.

Na região a presença espírita é tão significativa que a relação entre seus templos e seus habitantes é a mesma que a dos evangélicos - os quais possuem sete vezes mais locais de reunião na cidade - e bem superior a dos católicos. Ainda não temos como definir a razão dessa presença, mas uma explicação simples e possível é exatamente a que considera o perfil apresentado. $\mathrm{O}$ fato de haver menor presença das outras religiões, ou seja, de haver um "mercado de bens simbólicos" (Bourdieu, 1987) menos competitivo, foi propício para essa tradição religiosa ampliar sua presença no setor.

Em torno do Ribeirão Quatis encontramos um dos maiores bolsões de pobreza da cidade, representando essa região, com o Jardim Leonor e a área dos Cinco Conjuntos, os locais com maior concentração religiosa, a qual abrange as zonas norte e leste da cidade e os respectivos Setores 5, 7 e 4. Contudo, isoladamente, é no Setor 6 (Sul) que temos a maior concentração de locais de culto, principalmente com a presença de igrejas pentecostais que representam $50 \%$ na região (locais que se concentram nesse setor a partir do Cafezal, com forte presença no Jamile Dequech e no União da Vitória). Esses são bairros lembrados por sua maior violência, pobreza e ausência de assistência. Outro foco com grande presença de igrejas na região sul é o assentamento João Turquino ${ }^{8}$. Em relação comparação com o centro da cidade o número de templos católicos na zona sul é o dobro, e há vinte vezes mais locais de reunião espíritas e oito vezes mais de evangélicos.

\footnotetext{
${ }^{8}$ Em outras divisões propostas para a cidade o João Turquino encontra-se na Região Leste, abrangendo a área da UEL e do Shopping Catuaí.
} 


\section{Religiões na UEL}

Há como que um "tempo mítico" onde a universidade dos anos de 1970 era entendida como espaço de fazer política, de ser político. Os anos de 1990 encontram uma universidade repleta de religiosidade e passam a ser recorrentes as comparações de um presente religioso e esotérico em confronto com um passado político e engajado (Novaes, 1994). Na Universidade de Londrina as faixas em torno do calçadão ou os cartazes na Biblioteca indicam ativa presença das religiões por intermédio de quatro grupos organizados: NEU, GOU, ABU e PU.

A religiosidade entre estudantes universitários foi o tema da segunda rodada sobre religião do International Social Survey Programme, onde foi estudada a relação entre esoterismo, religião e política. Na UEL foram aplicados 254 questionários aos estudantes de 11 cursos, em amostra estratificada por ano de ingresso e área de estudo. A Tabela 3 apresenta os resultados relacionados à filiação religiosa.

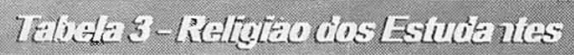

\section{RELIGIÃO}

Católica

Evangélico Tradicional

Evangélico Pentecostal

Espírita Kardecista

Religião Oriental

Afro-Brasileira

Outras

Nenhuma

Total

\begin{tabular}{|c|c|c|c|}
\hline $\begin{array}{l}\text { BRASIL } \\
\text { Estudantes }\end{array}$ & $\%$ & $\begin{array}{l}\text { LONDRINA } \\
\text { Estudantes }\end{array}$ & $\begin{array}{l}A \\
1 \\
1\end{array}$ \\
\hline 161 & 63,8 & 699 & 157,9 \\
\hline 26 & 10,3 & 99 & 8,2 \\
\hline 9 & $\begin{array}{l}3,6 \\
\end{array}$ & 44 & 3,6 \\
\hline 14 & I 5,6 & 147 & 12,2 \\
\hline 2 & I 0,8 & 10 & I 0,8 \\
\hline & 1 & 10 & 0,8 \\
\hline 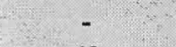 & i & 119 & 1,5 \\
\hline 40 & । 15,9 & 181 & 15,0 \\
\hline 254 & 100,0 & 1309 & i 100 \\
\hline
\end{tabular}

Fontes: IBGE-Censo Demográfico, 1991 e ISER, 2000

Nos resultados da pesquisa nas cinco universidades brasileiras estudadas chama atenção a forte presença do kardecismo (12\%), sendo que na UEL esse percentual apesar de alto é a metade da média brasileira encontrada na pesquisa. De um modo geral, desde o início do 
século o kardecismo aparece em pesquisas sobre o credo reliogioso com cerca de $1 \%$, o que indica uma atividade dessa religião dentro dos muros universitários bem mais intensa, de acordo com a origem social de seus fiéis: pessoas com maior escolaridade e brancas.

Em relação à religião evangélica podemos observar uma interessante inversão. Apesar de o percentual geral dos evangélicos em Londrina, estar num patamar próximo ao do brasileiro (sua projeção para o Brasil em 2001 é de $13 \%$ e encontramos $14 \%$ na UEL $^{9}$ ), geralmente temos $75 \%$ destes pertencentes a igrejas pentecostais, ao passo que na UEL esse percentual não passa de 30 . Com origem sócio-econômica inferior, os membros dessas igrejas ainda se encontram, em sua maioria, afastados da academia, sem condições de acesso à excludente universidade brasileira. Os evangélicos tradicionais, porém, como o próprio nome já indica, têm sua participação consolidada na sociedade - e mais ainda em Londrina - tanto nas classes mais baixas, como também nas classes médias e altas, tendo portanto acesso mais facilitado à universidade pública. No caso dos espíritas kardecistas também encontramos essa maior presença. O inverso ocorre entre os fiéis do candomblé e da umbanda, oriundos das classes mais baixas: poucos na cidade e "inexistentes" na universidade.

Por fim vale apontar a presença, tanto na UEL como nas outras universidades brasileiras, de um número também significativo de pessoas que se declararam sem-religião. O que também é compatível com a origem socioeconômica do grupo, como aponta levantamento de Pierucci \& Prandi (1996, p.225): “pode-se dizer que são o grupo mais masculino, que nada menos do que $17,2 \%$ têm o mais alto grau de instrução; que $25,6 \%$ são jovens entre 18 e 24 anos; que 50,3\% deles são seres metropolitanos; que sua taxa de ocupação (71,6\%) é das mais altas do País; e, finalmente, que a quantidade de 'sem-religião' com

\footnotetext{
${ }^{9}$ Não é possível definir o crescimento evangélico em Londrina entre 1991 e 2000 em razão de não termos disponíveis os valores de censos anteriores. Somente com os resultados do censo 2000 será possível iniciar estudos históricos em relação à religião na cidade. Provavelmente, o número de evangélicos não deverá ir alem dos $20 \%$. Na cidade do Rio de Janeiro o crescimento apontado foi esse (de $13 \%$ para $20 \%$ ), contudo em Londrina há ação católica mais ativa a qual pode ter contribuído para um menor crescimento evangélico.
} 
renda familiar mensal acima de vinte salários mínimos é o dobro $(12,1 \%)$ do verificado para o total de eleitores brasileiros $(6,3 \%)$ ".

Em relação às práticas religiosas entre os estudantes da UEL, encontramos, por exemplo, que apenas $8 \%$ dos respondentes afirmaram nunca realizar qualquer tipo de reza ou oração, lembrando que $15 \%$ se definiram como sem-religião. Para indicar a complexidade dessa situação, vale apontar que desses $27 \%$ rezam diariamente (!) e 7,5\% afirmaram que lêem a Bíblia semanalmente, o que apenas confirma a interpretação feita anteriormente de que não ter religião não pode ser lido como ateísmo ou mesmo agnosticismo. De qualquer forma constatamos que quase a metade dos sem-religião (47\%) não acreditam em Deus, como apontam os resultados da Tabela 4 .

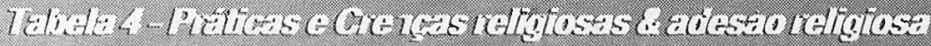

\begin{tabular}{|c|c|c|c|c|c|}
\hline $\begin{array}{l}\text { Religião } \\
\text { Estudantes entrevistados }\end{array}$ & $\begin{array}{c}\text { Católica } \\
158\end{array}$ & $\mid \begin{array}{c}\text { Evangélicos } \\
35\end{array}$ & $\begin{array}{c}\text { Espirita } \\
17\end{array}$ & $\left|\begin{array}{c}\text { Nenhuma } \\
40\end{array}\right|$ & $\begin{array}{c}\text { Total } \\
250\end{array}$ \\
\hline \multicolumn{6}{|l|}{ Práticas Religiosas } \\
\hline Reza diariamente & $69,7 \%$ & $94,3 \%$ & $82,4 \%$ & $27,5 \%$ & $72,5 \%$ \\
\hline Frequenta culto semanalmente & $39,5 \%$ & $62,9 \%$ & $35,3 \%$ & $25 \%$ & $36,5 \%$ \\
\hline LêaBiblia semanalmente & $19,3 \%$ & $60,0 \%$ & $23,6 \%$ & $7,5 \%$ & $23,4 \%$ \\
\hline \multicolumn{6}{|l|}{ Crenças relịgiosas } \\
\hline Deus & $96,2 \%$ & $100,0 \%$ & $94,1 \%$ & $53,8 \%$ & $90,0 \%$ \\
\hline Espírito Santo & $88,0 \%$ & $97,3 \%$ & $37,5 \%$ & $28,2 \%$ & $76,9 \%$ \\
\hline Diabo & $42,0 \%$ & $97,1 \%$ & - & $21,1 \%$ & $43,7 \%$ \\
\hline Anjos & $79,7 \%$ & $97,1 \%$ & $70,6 \%$ & $33,3 \%$ & $742 \%$ \\
\hline Virgem Maria & $88,1 \%$ & $29,0 \%$ & $58,8 \%$ & $28,9 \%$ & $69,3 \%$ \\
\hline Santos & $75,8 \%$ & $21,9 \%$ & $35,3 \%$ & $17,5 \%$ & $56,5 \%$ \\
\hline Céu & $62,2 \%$ & $97,1 \%$ & $25,0 \%$ & $23,1 \%$ & $58 \%$ \\
\hline Inferno & $41,7 \%$ & $97,1 \%$ & - & $17,5 \%$ & $35,4 \%$ \\
\hline
\end{tabular}

Fonte: ISER, 2000

Podemos perceber uma prática religiosa mais ativa entre os evangélicos, quadro já apontado para a realidade brasileira, sendo que, como indicam os resultados da Tabela 4, temos 63\% desses fiéis comparecem semanalmente aos locais de culto de suas igrejas. Entre os católicos 
esse percentual cai quase que pela metade, levando-nos novamente ao caráter nominal dessa religiosidade. Em relação aos espíritas temos um percentual ainda mais baixo que o dos católicos, também indicando uma religiosidade menos intensa entre os estudantes que professam essa religião no que se refere às reuniões. Ao observarmos os dados referentes à reza - prática individual eivada pelo coletivo, como nos lembra Mauss (1989) - encontramos a prática espírita mais próxima à evangélica, enquanto os católicos se situam mais abaixo, o que indica que a menor freqüiência dos espíritas nas reuniões não deve, necessariamente, ser lida como menor prática, se considerarmos a organização social do kardecismo.

As crenças nos ajudam a mapear melhor esses fiéis em relação à fidelidade que têm para com a doutrina de suas religiões. Inicialmente encontramos entre os espíritas um alto esclarecimento. Todos negam a existência do Diabo e do Inferno como também todos afirmam a crença na reencarnação, ponto central de sua crença. Entre as outras religiões, a única concordância total aparece entre os evangélicos, que afirmam $100 \%$ acreditar em Deus. De um modo geral há coerência entre opções religiosas e crenças; a exceção mais notória se dá entre os católicos dos quais $33 \%$ acreditam na reencarnação, crença rejeitada pela Igreja Católica.

\section{Considerações finais}

Alguns elementos devem ser salientados. Primeiramente devemos ter em mente que a maior presença de locais de culto evangélicos denota uma característica de sua forma de expansão. Os evangélicos caracterizam-se por grande "capilaridade social", ou o que a geógrafa Mônica Machado (1997) chamou de "territorialidade informal e fugaz" em oposição a "territorialidade formal e perene", adotada pela Igreja Católica ${ }^{10}$.

Temos na cidade de Londrina siginificativa presença evangélica, demarcada pela existência de instituições de ensino, pelo Hospital Evangélico e por uma aceitação generalizada do grupo na sociedade. Nas formaturas da UEL, por exemplo, a presença de um padre e de um pastor é uma constante. Essa característica da cidade levou a realiza- 
ção da pesquisa Projeto Londrina 2000 e em seu relatório o coordenador Lourenço Kraft aponta esse perfil da cidade:

Em comparação com o restante do Brasil, Londrina apresenta uma igreja muito mais forte. Enquanto a média de habitantes por igreja do país como um todo é mais ou menos 2.500 , Londrina tem 1.200, ou seja Londrina é duas vezes mais alcançada do que o restante do país. Enquanto $7 \%$ da população vai à igreja em Londrina, somente 3 a $4 \%$ participa no restante do país, e existem lugares, como o sertão nordestino, com menos de $1 \%$ da população nas igrejas (Kraft, 2000).

Em relação à participação também os católicos têm uma participação ativa, seja por meio de grupos carismáticos, seja por intermédio de pastorais vinculadas ou não à teologia da libertação. As igrejas católicas encontram-se nos finais de semana sempre cheias e, como ficou demarcado nas eleições municipais de 2000 , sua presença e ação no seio da sociedade é significativa. Mesmo com menor presença institucional do que os evangélicos, a distribuição católica na cidade é ampla com maior presença nas regiões mais pobres.

Em relação aos espíritas, chama atenção a baixa presença de fiéis de candomblé e de umbanda conforme o censo de 1991 (Tabela 1) ao lado de um bom número de locais de reunião dessas religiões $(35$, segundo pesquisa SEPAL), já que para cada 20 pessoas que declararam pertencer à religião corresponde um local de reunião. Essa questão aponta para o tema já recorrente na sociologia relativo à religião de dupla pertença; no caso, ser católico e frequientar rituais do candomblé ou da umbanda.

De um modo geral a religiosidade na cidade de Londrina assemelha-se à da sociedade brasileira, sendo que na cidade há uma presença cristã (evangélicos e católicos) mais significativa. Os espíritas

10 "A Igreja Católica tende a não apresentar mudanças, no tempo e no espaço, em sua área de atuação. Uma lógica completamente diferente é desenvolvida pelas Igrejas Pentecostais. Mudando temporal e especialmente, as igrejas pentecostais conseguem difundir-se de maneira bastante significativa. Este movimento religioso possui e desenvolve uma especifica forma espacial de controle social essencialmente dinâmica, caracterizada pela transitoriedade e efemeridade" (Machado, 1997, p.230). 
encontram-se à margem e os orientais têm maior relevância devido à composição étnica da população. O grupo dos sem-religião, mesmo que significativo é menor do que os grupos existentes no país, devido provavelmente à uma ação mais significativa do "catolicismo internalizado" na cidade.

Em relação à religiosidade na UEL ainda estamos na fase preliminar de nossa análise. Após a aplicação dos questionários foram realizadas 16 entrevistas qualitativas com estudantes e também foi realizada observação quanto à participação nas reuniões dos grupos religiosos existentes no câmpus. O objetivo deste texto foi mapear de forma geral a presença religiosa na cidade de Londrina, indicando algumas peculiariedades em relação ao conteúdo das crenças adotadas e sua distribuição geográfica na cidade para situarmos de forma mais ampla a religiosidade encontrada entre os estudantes da UEL. Com base nos dados de nossa pesquisa estaremos desenvolvendo, em seguida, uma análise em que compararemos a filiação religiosa dos universitários, suas práticas religiosas ou esotéricas, seus valores morais e sua participação política no câmpus e na sociedade.

\section{Referências Bibliográficas}

ADOLFO, Sérgio Paulo. O Mito Cosmogônico e o Candomblé de Londrina. Unopar Científica, Londrina, v.1, n.1, 1997.

BOURDIEU, Pierre. A Economia das Trocas Simbólicas. São Paulo: Perspectiva, 1987.

CAMARgo, Cândido Procópio Ferreira. Católicos, protestantes, espíritas. Petrópolis, Vozes, 1973.

CONCONE, Maria Helena. Umbanda, uma religião brasileira. São Paulo: FFLCH, 1987 .

D'EPINAY, Christian Lalive . Religion, Dynamique Social et Dépendence: les Mouvements Protestants en Argentine et au Chili. Paris, Mouton, 1975.

FERNANDES, Rubem César. Governo das almas: As denominações evangélicas no Grande Rio. In: Nem Anjos nem Demônios. Petrópolis: Vozes, 1994. 
FONSECA, Alexandre Brasil. Religiões e Meios de Comunicação: possibilidades na Construção da Cidadania. Rio de Janeiro, Koinonia, 1995. (Tempo e Presença, 281)

FONSECA, Alexandre Brasil. Evangélicos e Mídia no Brasil. Dissertação (Mestrado)- Universidade Federal do Rio de Janeiro. Rio de Janeiro, 1997.

FONSECA, Alexandre Brasil. Nova Era Evangélica, Confissão Positiva e o Crescimento dos sem-religião. Numem: Revista de Estudos e pesquisa da religião, Juiz de Fora, v.3, n.3, (no prelo).

GARÇONI, Ines \& VILAS, Juliana. Religiao e Voto. Isto é, São Paulo, Editora Três, 2000. Disponível em: <http://www.terra.com.br/istoe/reportagens/ religiao.htm>. Acesso em: 26 nov. 2000.

GIUMBELLI, Emerson. O Cuidado dos Mortos: uma História da Condenação e Legitimação do Espiritismo. Rio de Janeiro, Arquivo Nacional, 1997.

GÓMEZ, Jorge. El Crescimiento y la Deserción en la iglesia evangélica costarricense. San José, IINDEF, 1996.

KRAFT, Lourenço. Londrina 2000: Uma Pesquisa com Propósito! São Paulo, 2000. mimeo.

LEITE, Ivana de Arruda (1996). A oração dos doutores: um estudo sobre a religiosidade dos intelectuais. 1996. Dissertação (Mestrado) - FFLCH, Universidade de São Paulo. São Paulo, 1996.

MACHADO, Monica Sampaio. A lógica da reprodução pentecostal e sua expressão espacial. In: SANTOS, Milton (Org.). O novo mapa do mundo: fim de século e globalização. São Paulo, Hucitec \& ANPUR, 1997.

MARIANO, Ricardo. Neopentecostalismo: por uma sociologia dos novos pentecostais. São Paulo, Loyola, 1999.

MARIZ, Cecília. Religion and Coping with Poverty in Brazil. 1989. PhD (Dissertation) - Boston University. Boston, 1989.

MAUSS, Marcel. Ensaios de sociologia. São Paulo, Perspectiva, 1989.

NOVAES, Regina. Religião e política: sincretismos entre alunos de Ciências Sociais. Rio de Janeiro, ISER, 1994. (Comunicações do ISER, 45).

PAIVA, Geraldo José. Representação social da religião em docentes-pesquisadores universitários. Revista de Psicologia da USP, São Paulo, v.10, n.2, 1999.

PIERUCCI, Antônio Flávio; PRANDI, Reginaldo. A realidade social das religióes no Brasil. São Paulo: Hucitec, 1996. 
PIERUCCI, Antônio Flávio. Reencantamento e dessecularização: a propósito do auto-engano em sociologia da religião. São Paulo, CEBRAP, 1997. (Novos Estudos Cebrap, 49).

PRANDI, Reginaldo. Perto da magia, longe da política. In: PIERUCCI. Antônio Flávio \& PRANDI, Reginaldo. A realidade social das religiōes no Brasil. São Paulo, Hucitec, 1996.

As herdeiras do Axé. São Paulo, Hucitec, 1996a.

PIQUET CARNEIRO, Leandro ; SOARES, Luiz Eduardo. Religiosidade, estrutura social e comportamento político. In : BINGEMER, Maria Clara (Org.). O Impacto da modernidade sobre a religião. São Paulo : Loyola, 1992.

STEIL, Carlos. A Igreja dos pobres: da secularização à mística. Religião e Sociedade, Rio de Janeiro,v.19, n.2, 1998.

\section{Abstract}

Based on a survey made in the year 2000 about religions in Londrina, we discuss the religious presence in this city in order to provide elements which may help the perception of the extension and general characteristics of the creeds in practice. Our main focus is on four groups: the Catholics, the Evangelicals, the Spirituals and the "non-religious", highlighting their general conformation in Brazil and the geographical distribution of places for religious services and masses in the city. Some preliminary data of the International Study of Esoterism and Religion, which has been carried out in fifteen countries of three continents between 1999 and 2000 and which is part of the second round about religion of the International Social Survey Programme, are also presented. In early 2000 the field work was accomplished and the information tabulation and analysis was started. In Brazil, the research was carried out in Londrina State University and in four other universities. In the conclusion we indicate local peculiarities of the religions in comparison with the national context and point out possible ways to be followed in our research about the religious practice of university students in Londrina.

Key-words: religious practice in Londrina; religions; university students. 